\title{
Latitudinal differences in Mytilus californianus thermal physiology
}

\author{
Cheryl A. Logan ${ }^{1,2, *}$, Laurie E. Kost ${ }^{1}$, George N. Somero ${ }^{1}$ \\ ${ }^{1}$ Hopkins Marine Station, Department of Biology, Stanford University, Pacific Grove, California 93950, USA \\ ${ }^{2}$ Present address: California State University, Monterey Bay, Seaside, California 93955, USA
}

\begin{abstract}
The California ribbed mussel Mytilus californianus (Conrad 1837) is a dominant intertidal species that ranges from Alaska (USA) to Baja California (Mexico) along the west coast of North America. Despite its broad latitudinal range, which results in populations living at widely different temperatures, multiple studies have concluded that this species is genetically homogenous. This may be due to high gene flow, which would inhibit local adaptation, and lack of strong post-settlement selection pressure, which would not favor shifts in allelic frequencies among sites. We investigated several physiological traits that show temperature-adaptive variation in other Mytilus species. We sampled populations of $M$. californianus at 7 sites across $33^{\circ}$ of latitude to test for the possibility of local adaptation or phenotypic plasticity. Individuals acclimated to common conditions were examined for possible differences in whole-organism thermal tolerance. The most northern population (Tatoosh Island) had a significantly lower survival rate following an acute heat stress event than the other populations. Additional physiological processes were examined that affect thermal optima and limits: critical thermal maximum (Hcrit) of cardiac function and metabolic capacity (as indexed by tissue activity of an indicator enzyme, malate dehydrogenase). Tatoosh mussels had a significantly lower Hcrit than other sites, indicating that this population may be adapted to cooler conditions compared to other populations. Metabolic activity did not correlate with latitude of collection. Phenotypic plasticity at the adult stage did not explain differences in thermal tolerance. Thus, genetic differences (local adaptation or balanced polymorphism), developmental plasticity, maternal effects, or within-site thermal heterogeneity may be responsible for the observed variation among populations.
\end{abstract}

KEY WORDS: Adaptation - Environmental variability - Latitudinal differences · Mytilus · Physiology $\cdot$ Stress $\cdot$ Temperature $\cdot$ Phenotypic plasticity

\section{INTRODUCTION}

Marine benthic invertebrates with life cycles that include a pelagic phase are thought to have greater dispersal distances, lower genetic differentiation, and better-connected populations than species whose life histories lack a pelagic phase (Roughgarden et al. 1985, Possingham \& Roughgarden 1990, Farrell et al. 1991, Gaines \& Bertness 1992, Alexander \& Roughgarden 1996, Caley et al. 1996, Kuo \& Sanford 2009). However, some of these species historically charac- terized as demographically open may be more genetically structured than previously thought (Palumbi 2004, Levin 2006, Kelly \& Palumbi 2010). The California ribbed sea mussel Mytilus californianus, a dominant competitor in mid-intertidal communities along the west coast of North America, has a pelagic larval duration of between 9 and 45 d (Trevelyan \& Chang 1983, Strathmann 1987). Several studies have concluded that there is no genetic structure at several independent types of genetic markers across the range of M. californianus (Bayne 1976, Levinton \& 
Suchanek 1978, Sarver \& Foltz 1993, Addison et al. 2008), which extends over $4000 \mathrm{~km}$ and across $33^{\circ}$ of latitude from Baja California (Mexico) to the Gulf of Alaska (USA). Addison et al. (2008) attributed the genetic homogeneity they found in $M$. californianus to high gene flow (due to a long pelagic larval duration and year-round spawning), but also suggested that lack of a strong selective gradient across its range, rather than high gene flow per se, might be a key element underlying the broad-scale genetic homogeneity.

Several strong and persistent environmental gradients do occur in the rocky intertidal environment along the west coast of North America, including water and air temperatures, $\mathrm{pH}$, and nutrients (Menge et al. 1997, Helmuth et al. 2006, Feely et al. 2008). Genetic differentiation can occur under high gene flow conditions, and populations that are homogeneous in neutral loci may still exhibit local adaptation in functionally important traits (Hedgecock 1986, Conover et al. 2006). Perhaps the most relevant selective pressure to intertidal mussels is the strong gradient in air and water temperatures that occurs across the range of Mytilus californianus (Helmuth et al. 2006). Temperature can be a strong selective force on physiological characters via natural selection (Hedgecock 1986), yet physiologically different populations can also arise due to phenotypic plasticity (Hochachka \& Somero 2002). Teasing apart physiological differences due to local adaptation versus phenotypic plasticity is important since plasticity can mimic adaptation (Kawecki \& Ebert 2004).

Over broad scales, a north to south thermal gradient exists along the west coast of North America, and this can be reflected in mussel body temperatures. Studies by Helmuth et al. $(2002,2006)$ using 'robomussels' (mussel shells encasing a small data logger embedded in silicon rubber that yields body temperatures similar to those of live mussels) revealed a strong north to south gradient in maximal and average temperatures: in the mid-intertidal zones at Tatoosh Island, Washington, and Alegria, California, USA ( 1620 km or $14^{\circ}$ in latitude apart), yearly maximal temperatures were $25.4^{\circ} \mathrm{C}$ and $39.5^{\circ} \mathrm{C}$, respectively, and mean annual temperatures were $9.9^{\circ} \mathrm{C}$ and $15.7^{\circ} \mathrm{C}$, respectively (Helmuth et al. 2006, see their Table 3). However, due to differences in the timing of daytime low tides and varying amounts of fog and cloud cover among sites, a thermal mosaic is found for mussels at more localized scales. 'Hot spots,' or sites with a maximal daily temperature warmer than expected based on a latitudinal gradient, reveal a more complex and patchier distribution of body temperatures along the west coast (Helmuth et al. 2006).

The possibility that variations in temperature among sites along the broad latitudinal range of Mytilus californianus might favor adaptation to local thermal conditions is suggested by studies of the thermal physiology of 2 other Mytilus congeners whose biogeographic ranges along the west coast of North America span that of ribbed mussels (reviewed by Lockwood \& Somero 2011). M. trossulus, a blue mussel native to the North American west coast, occurs from the Arctic Ocean to central California. M. galloprovincialis, an invasive blue mussel from the Mediterranean Sea, extends from central California into Baja California (Braby \& Somero 2006a). $M$. galloprovincialis has demonstrated a more warmadapted physiology than $M$. trossulus in laboratory studies of heart function, enzyme kinetic properties, tissue enzyme activity levels, and the heat shock response (Hofmann \& Somero 1996, Fields et al. 2006, Braby \& Somero 2006b, Lockwood \& Somero 2011). Given that the latitudinal range of $M$. californianus is similar to the combined west coast ranges of both blue mussels, temperature-adaptive variation among populations of ribbed mussels in traits known to differ adaptively between native and invasive blue mussels might be expected.

Here, we investigated possible differences in thermal physiology in 7 populations of Mytilus californianus sampled from Tatoosh Island in Washington to Punta Morro in Baja California, a distance exceeding $2000 \mathrm{~km}$. We sampled mussels from the mid-intertidal zone near locations where 'robomussel' temperature data loggers had previously been installed (B. Helmuth pers. comm.). We acclimated them to common conditions for at least $6 \mathrm{wk}$ and measured (1) survival rates following exposure to acute thermal stress, (2) the temperature at which heart rate fails under acute heat stress, and (3) steady-state metabolic rates (indexed by the activity of malate dehydrogenase (MDH), an enzyme involved in ATP production under aerobic and anaerobic conditions). By acclimating mussels to common thermal conditions, we aimed to eliminate thermal tolerance differences due to field acclimatization (Sanford \& Kelly 2011).

We hypothesized that acclimation to common conditions would eliminate site-to-site differences in thermal tolerance and metabolic rate if this species is a genetically homogenous species. If site-to-site differences are observed, differences may reflect previously undetected genetic differentiation (e.g. local adaptation), particularly if they mirror a latitudinal 
gradient or the thermal mosaic described above. However, certain types of phenotypic plasticity are impossible to eliminate without breeding and raising individuals from different populations through 2 or more generations in the laboratory. Thus, any thermal tolerance differences found among acclimated mussels could also be the result of phenotypic plasticity that became fixed during development or nongenetic influences of the maternal environment on offspring phenotype.

\section{MATERIALS AND METHODS}

\section{Mussel collection and acclimation to common conditions}

Approximately 200 mussels between 7.5 and $9.5 \mathrm{~cm}$ in length were collected from the mid-intertidal zones at 7 locations (Fig. 1, Table 1) between 7 June and 10 July 2009: Tatoosh Island, Washington $\left(48^{\circ} \mathrm{N}\right)$, Port Townsend, Washington $\left(48^{\circ} \mathrm{N}\right)$, Boiler Bay, Oregon $\left(44^{\circ} \mathrm{N}\right)$, Bodega Bay, California $\left(38^{\circ} \mathrm{N}\right)$, Pacific Grove, California ('Hopkins,' $36^{\circ} \mathrm{N}$ ), Ventura, California ('Mussel Shoals,' $34^{\circ} \mathrm{N}$ ) and Punta Morro, Baja California $\left(31^{\circ} \mathrm{N}\right.$; Fig. 1). 'Hot spots,' characterized by extremes of high temperature compared to what might be expected based on a latitudinal gradient (Helmuth et al. 2006), are labeled in Fig. 1. Boiler Bay and Alegria, California, were 2 'hotspots' identified by Helmuth et al. (2006) at or near our sites. The Alegria site is similar in topography to our Mussel Shoals site and is also located within the Southern California Bight (K. R. S. Mislan et al. unpubl.); therefore, it is labeled as a potential 'hotspot.' In addition to these designations, Port Townsend is also much hotter than expected based on latitude alone due to its inland

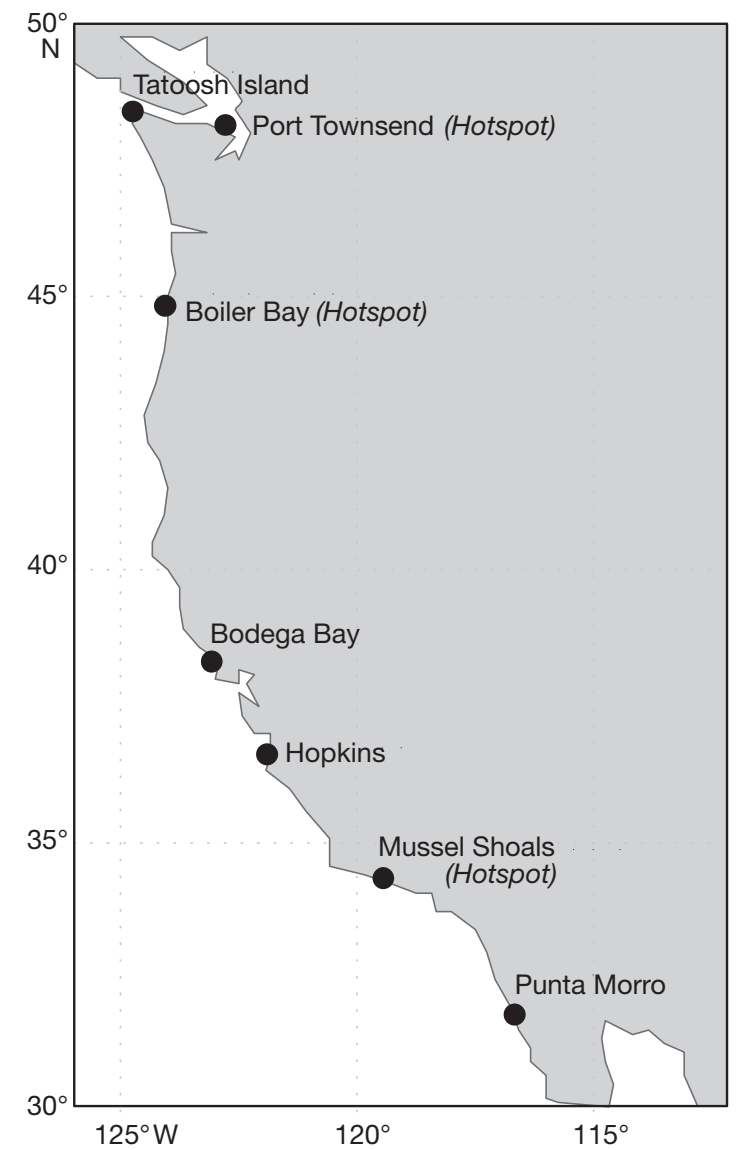

Fig. 1. Mytilus californianus collection sites along the west coast of North America. Mussels were collected during the June 2009 spring tide series. Sites are labeled 'Hotspot' if the site is warmer than expected based on latitude alone (see 'Materials and methods')

location in the Strait of Juan de Fuca, where mussels experience less fog, lower wave intensity, and an increased frequency of midday lower low tides (Helmuth \& Harley 2003).

Table 1. Collection site latitude and longitude, date (mm/dd/yy) of collection and arrival at the lab, tidal height (cm above mean low low water), and approximate wave exposure. HMS: Hopkins Marine Station

\begin{tabular}{|c|c|c|c|c|c|c|}
\hline Collection site & $\begin{array}{l}\text { Latitude } \\
\qquad(\mathrm{N})\end{array}$ & $\begin{array}{l}\text { Longtitude } \\
\text { (W) }\end{array}$ & $\begin{array}{c}\text { Date of } \\
\text { collection }\end{array}$ & $\begin{array}{l}\text { Arrival } \\
\text { at HMS }\end{array}$ & $\begin{array}{l}\text { Tidal height } \\
\text { (cm) }\end{array}$ & Exposure \\
\hline Punta Morro, Baja California, Mexico & 31.861 & 116.666 & 20/6/09 & $22 / 6 / 09$ & $\sim 88^{\mathrm{a}}$ & Semi-protected \\
\hline 'Mussel Shoals,' Ventura, CA, USA & 34.355 & 119.442 & $17 / 6 / 09$ & 17/6/09 & $\sim 110^{\mathrm{b}}$ & Semi-protected \\
\hline HMS, Pacific Grove, CA, USA & 36.621 & 121.905 & 7/6/09 & 7/6/09 & $171^{\mathrm{c}}$ & Exposed \\
\hline Bodega Bay, CA, USA & 38.318 & 123.074 & 9/6/09 & 9/6/09 & $\sim 118^{\mathrm{b}}$ & Exposed \\
\hline Boiler Bay, OR, USA & 44.831 & 124.059 & $17 / 6 / 09$ & 19/6/09 & $107^{\mathrm{c}}$ & Exposed \\
\hline Tatoosh Island, WA, USA & 48.391 & 124.740 & 9/6/09 & 10/6/09 & $81.4^{\mathrm{c}}$ & Exposed \\
\hline Port Townsend, WA, USA & 48.144 & 122.777 & 10/7/09 & 10/7/09 & $170^{\mathrm{c}}$ & Protected \\
\hline
\end{tabular}


Fifty mussels were immediately frozen on dry ice at all locations except Port Townsend and Punta Morro. Live and frozen mussels were shipped overnight to Hopkins Marine Station within $24 \mathrm{~h}$ of collection. Frozen mussels were stored at $-80^{\circ} \mathrm{C}$. Live mussels were kept in mesh bags $\left(\sim 25\right.$ ind bag $\left.^{-1}\right)$ in shaded outdoor tanks with high-flow sand-filtered seawater from Monterey Bay. Mesh bags were randomly assigned to 4 identical flow-through seawater tanks. Bags were rotated between tanks periodically to avoid potential tank differences. Temperature in the flow-through tanks followed the ambient temperatures of Monterey Bay $\left(\right.$ mean $=13.9^{\circ} \mathrm{C}$, range $=$ $\left.10.7-17.3^{\circ} \mathrm{C}\right)$. Mussel survival was determined at least once weekly, and mortality was low $(<5 \%$ over 6 mo). Mussels were fed 3 times $\mathrm{wk}^{-1}$ with a phytoplankton mix (Reed Mariculture, Shellfish Diet 1800 Formula).

Mussels were held in common acclimation conditions for a minimum of $6 \mathrm{wk}$ and a maximum of $6 \mathrm{mo}$, depending on the physiological experiment. It was necessary to prioritize the timing of experiments to ensure that enough individuals would be available from all sites to complete most or all the physiological measurements with appropriate sample sizes. Acclimation duration is provided in each experiment.

\section{Survival following acute thermal stress}

Following 6 mo of acclimation to common conditions, 10 mussels from each site were prepared for acute thermal stress survival experiments. Mussels were removed from mesh bags and placed in small plastic containers with several holes $(21 \times 7 \times 4.5 \mathrm{~cm})$. Thermocouples were inserted into the tissue of 4 non-experimental mussels that would later be connected to a temperature controller unit to control heating rate. Containers were then placed back in ambient seawater tanks for $\sim 2 \mathrm{~h}$ before the beginning of the experiment.

Meanwhile, inside the lab, 2 large Styrofoam boxes $(30 \times 35 \times 85 \mathrm{~cm})$ were prepared for heat ramp experiments in air. Boxes were set up inside a cold room $\left(\sim 4^{\circ} \mathrm{C}\right)$ to allow for accurate control of the temperature ramp rate. Each box was equipped with an Omega rubber heating mat (Model SRMU020230, $120 \mathrm{~V}, 1.25 \mathrm{~A}, 2 \times 30$ inches, $\sim 5 \times 76 \mathrm{~cm}$ ) and a controller unit (Omega Autotune Temperature Controller CSC32). Mussels from 3 sites were placed in 1 Styrofoam box, and mussels from the other 4 sites were placed in the other. Several preliminary runs were performed to ensure that the ramp rate was identical between boxes. Lids were placed on the Styrofoam boxes to ensure constant heating rates. The heat ramp began with mussel temperatures starting at 12 to $13^{\circ} \mathrm{C}$. To test survival in response to a simulated hot day during low tide, we ramped air temperature inside the Styrofoam box at a rate of $8^{\circ} \mathrm{C}$ $\mathrm{h}^{-1}$ to $36^{\circ} \mathrm{C}$, held a constant temperature at $36^{\circ} \mathrm{C}$ for $1 \mathrm{~h}$, and then immediately returned mussels to flowthrough seawater tanks at ambient temperature $\left(\sim 13.9^{\circ} \mathrm{C}\right)$. This heating rate is high, but realistic for a very hot day and has been measured in situ for robomussels (Gracey et al. 2008, K. A. Smith pers. comm.). The final holding temperature $\left(36^{\circ} \mathrm{C}\right)$ was chosen based on preliminary experiments.

After the acute heat stress event, mussel mortality was assessed daily for $2 \mathrm{wk}$ by squeezing the valves together and looking for movement or closure. Mussels were marked as 'alive' if they closed easily, 'moribund' if they were slightly gaping but would not close, or 'dead' if they were gaping $>1 \mathrm{~cm}$. A nonparametric log-rank (Mantel-Cox) test $(\mathrm{p}=0.05)$ was used to assess survival by comparing survival distributions with the null hypothesis that the survival curves were identical in all populations (Graphpad Software).

\section{Heart rate and critical temperature measurements}

To determine whether site-specific differences in the thermal tolerance of cardiac function exist for Mytilus californianus, we measured heart rates (beats $\mathrm{min}^{-1}$ ) in 13 to 15 mussels site ${ }^{-1}$ to identify the critical temperature at which heart rate fails during an acute heat stress (Hcrit). We used specimens that had been acclimated to common conditions for at least 6 wk and not more than 6 mo from 6 of our sites (we did not have enough mussels in the correct size class from Port Townsend). Mussels from different sites were randomly drawn for experiments throughout the 5 mo experimental period. The long time required to complete heart rate experiments on such a large number of individuals was unavoidable due to logistical constraints.

Heart rates were measured using impedance pneumography following the methods of Braby \& Somero (2006b). We drilled 2 small holes $(<1 \mathrm{~mm}$ diameter) in each valve immediately exterior to the pericardial space at the posterior end of the hinge region. Fine copper electrodes (40-gauge magnet wire, with $2 \mathrm{~mm}$ of tip exposed) were inserted into the pericardial space and held in place with fastdrying glue (Super Glue ${ }^{\mathrm{TM}}$ - Gel Formula). Another 
hole was drilled $(<1 \mathrm{~mm}$ diameter) in the posterior ventral region, and a T-type thermocouple was inserted and secured with Super Glue. To measure heart rates, an analog impedance signal was converted to a voltage signal (UFI, Impedance Converter model 2991) and digitally recorded using a data acquisition system (ADInstruments, PowerLab/16SP), sampling at $100 \mathrm{~Hz}$. Internal mussel temperatures were measured using $\mathrm{HOBO}^{\circledR}{ }^{\circledR}$ temperature loggers (Onset ${ }^{\circledR}$ ).

Mussels were held in small rectangular plastic containers $(7 \times 7 \times 4.5 \mathrm{~cm})$ filled with $\sim 1 \mathrm{~cm}$ of seawater to maintain a humid environment. Containers were placed on a metal rack inside a closed Styrofoam box equipped with a controlled heating element (as described above) and a small air circulation fan. Chamber temperature, mussel temperature, and heart rates of up to 6 mussels could be recorded simultaneously during an experiment.

To test the response of heart rate to a simulated hot day during low tide, we ramped the air temperature inside the Styrofoam box at a rate of $8^{\circ} \mathrm{C} \mathrm{h}^{-1}$. Initial air temperature was maintained at $\sim 13^{\circ} \mathrm{C}$ using ice packs during mussel preparation. Ice packs were removed at the start of the temperature ramp. The ramp was terminated when all mussels' heart rates ceased. A single experiment could be run per day and lasted for approximately 6 to $8 \mathrm{~h}$, including preparation time.

Heart rates were manually counted for a $1 \mathrm{~min}$ interval every 5 min during the heat ramp and then plotted against individual mussel temperature. To determine whether Hcrit varied significantly among mussel populations, the common solution of the best-fit lines before and after the distinct shift in heart rate on an Arrhenius plot was identified (Braby \& Somero 2006b). Sample populations were tested for parametric assumptions of equal variance (Bartlett's test) and normality (Lillefor's test). These assumptions were satisfied, and 1-way analysis of variance (ANOVA) was used to test the null hypothesis that all individuals were drawn from populations with the same mean Hcrit. Student-Newman-Keuls (SNK) post hoc test was used to assess pairwise significance (alpha $=0.05)$.

\section{Metabolic enzyme activity}

Malate dehydrogenase (MDH) is involved in several metabolic functions including the citric acid cycle, the transfer of reducing equivalents across the mitochondrial membrane, and in the bivalve anaero- bic pathway of ATP generation (Hochachka \& Somero 2002). MDH activity is correlated with oxygen consumption in mussels and is thought to be a good biochemical proxy for metabolic rate (Dahlhoff \& Menge 1996, Dahlhoff et al. 2002, Dahlhoff 2004). Within a tissue, activity of MDH is determined by its catalytic efficiency (a genetically determined characteristic), enzyme production (transcription and translation), inhibition or activation (e.g. negative feedback), a change in the cellular environment (e.g. $\mathrm{pH}$ or temperature), or post-translational modification. We assessed MDH activity in mussels at the time of collection (field-acclimatized) and after acclimation to common conditions for at least 2 mo.

To assess field-acclimatized enzyme activities at each site, 10 mussels that had been flash frozen immediately upon collection were thawed on ice, weighed, and dissected to remove pieces of adductor muscle. The tissue was immediately homogenized in 10 volumes of ice-cold $50 \mathrm{mM}$ potassium phosphate buffer ( $\mathrm{pH} 6.8$ at $20^{\circ} \mathrm{C}$ ) using a stainless steel bead in a Qiagen Tissuelyser. Field-acclimatized samples came from 5 sites: Tatoosh Island, Boiler Bay, Bodega Bay, Pacific Grove ('Hopkins'), and Ventura ('Mussel Shoals'). To assess enzyme activities from mussels that had been acclimated to common conditions, 10 mussels from each of the 7 sites were removed from common-condition tanks after 2 mo and dissected immediately. Adductor tissue was flash frozen in liquid nitrogen, thawed on ice, weighed, and immediately homogenized as for the field-acclimatized specimens. Tissue homogenates were centrifuged in a Labnet refrigerated microcentrifuge at $17500 \times g$ $\left(30 \mathrm{~min}\right.$ at $4^{\circ} \mathrm{C}$ ). The supernatant was transferred into fresh tubes and spun for an additional 5 min. The resultant supernatant was divided into aliquots, flash frozen in liquid nitrogen, and stored at $-80^{\circ} \mathrm{C}$. Aliquots were thawed on ice immediately prior to assaying enzyme activity.

Enzymes were assayed spectrophotometrically using a temperature-controlled microplate reader (Infinite F200 with Injection, TECAN Group) following methods modified from Yang \& Somero (1993). The TECAN temperature was controlled at $25 \pm$ $0.2^{\circ} \mathrm{C}$, and activity rates are reported in International Units per gram wet (fresh) weight ( $\left.\mathrm{IU} \mathrm{g}^{-1} \mathrm{fw}\right)$. MDH was assayed in $200 \mathrm{mM}$ imidazole- $\mathrm{HCl}, \mathrm{pH} 7.0$ at $20^{\circ} \mathrm{C}, 200 \mu \mathrm{M}$ oxaloacetate, and $150 \mu \mathrm{M}$ NADH. We loaded $2.5 \mu \mathrm{l}$ of protein homogenate per well into 2 rows of a black 96-well microplate (Corning). The first 3 wells were left empty (blanks), and individual homogenates were loaded in triplicate thereafter $\left(7\right.$ ind. run $\left.^{-1}\right)$. MDH enzyme cocktail $(198 \mu \mathrm{l}$ at $25 \pm$ 


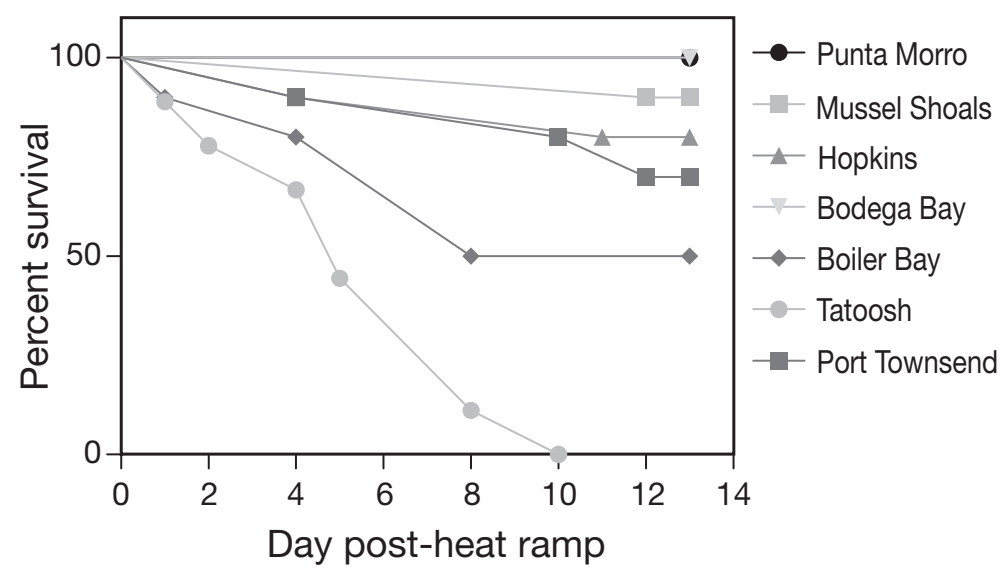

Fig. 2. Survival proportions of Mytilus californianus populations following an acute heat stress event (after acclimation to common conditions for $\sim 6$ mo). Mussels were heated in air to $36^{\circ} \mathrm{C}$, held for $1 \mathrm{~h}$, returned to seawater, and monitored for survival. Tatoosh mussels had significantly lower survival than mussels from all other sites except Boiler Bay. A log-rank test showed a significant relationship between latitude and survival $(p=0.0002)$

$0.2^{\circ} \mathrm{C}$ ) was injected at a rate of $150 \mu \mathrm{l} \mathrm{s}{ }^{-1}$ into each well, orbitally shaken for $1 \mathrm{~s}$ (amplitude $=2.5 \mathrm{~mm}$ ), and read at $340 \mathrm{~nm}$ absorbance 9 times s$~^{-1}$ (3 flashes read $^{-1}$ ) for $20 \mathrm{~s}$. The linear portion of the reaction (typically 4 to $14 \mathrm{~s}$ ) was used to calculate the slope (activity).

Triplicate values were averaged to determine mean MDH activity for each individual. Site populations satisfied parametric assumptions for normality and equal variance, and 1-way ANOVA was used to test the null hypothesis that all individuals were drawn from populations with the same mean MDH activity. An SNK post hoc test was used to examine pairwise significance between sites (alpha $=0.05)$.

\section{Sequencing of cMDH at position 114}

Previous work has described differences in kinetic properties of the cytosolic form of MDH (cMDH) in Mytilus congeners that result in temperature compensation for warm- versus cold-adapted blue mussel enzymes (Fields et al. 2006). Preliminary data showed the possibility of differences in cMDH kinetic properties (Michaelis-Menten constant for cofactor $\mathrm{NADH}, \mathrm{K}_{\mathrm{m}}{ }^{N A D H}$ ) between mussels collected in this study as well (data not shown). Therefore, we investigated the possibility of a mutation in the $\mathrm{cMDH}$ genes at codon 114 (Fields et al. 2006) that could underlie any potential differences. Codon 114 is known to differ between the 2 blue mussel congeners and $M$. californianus in a nonconservative amino acid substitution that is responsible for the differences found in substrate affinity (Fields et al. 2006).

We dissected a small piece of foot tissue from the same 10 acclimated mussels per site that were used for the enzyme activities. Genomic DNA was extracted from each sample using a NucleoSpin DNA extraction kit (BD Biosciences). A segment of the cytosolic gene for MDH was amplified by polymerase chain reaction using the following primers: FWD270 (5' GCC TAG AAG GGA AGG AAT GG 3') and RVS388 (5' ATT GGT ATT GGC TGG ATT TCC 3') and an AmpliTaq PCR Master Mix (Applied Biosystems). The PCR step-up profile consisted of $94^{\circ} \mathrm{C}$ (2 min), 34 cycles of $94^{\circ} \mathrm{C}(30 \mathrm{~s}), 61^{\circ} \mathrm{C}(45 \mathrm{~s})$, and $68^{\circ} \mathrm{C}(80 \mathrm{~s})$, and a final extension at $68^{\circ} \mathrm{C}(10 \mathrm{~min}) . \mathrm{PCR}$ products were cleaned and sequenced with primer FWD270 at Sequetech Corporation (Mountain View, CA). Sequences were aligned and edited using the program Sequencher version 4.9 (Gene Codes Corporation).

\section{Size and gonadosomatic index (GSI)}

All mussels used in this study were measured for size (length and width), and specimens used in the enzyme activity study were assessed for reproductive status. GSI was not examined in mussels that underwent survival or heart rate experiments because the acute heating regime itself often induces spawning during the experiment (this behavior was not visually assessed during the experiment because mussels were in closed containers). To determine GSI, we separated somatic and gonadal tissues, dried them until brittle, and then weighed each tissue separately. GSI was determined by dividing the gonadal tissue weight by the sum of the somatic and gonadal tissue weights (Petes et al. 2008). For mussels used in the enzyme analysis, the somatic tissue weight does not include gill or adductor muscle (these tissues were frozen for subsequent analysis). GSI comparison between sites should not be affected by absence of these tissues since these tissues roughly made up the same percent of the total somatic weight across sites (C. Logan pers. obs.). Therefore, our GSI values are significantly higher than those found elsewhere in the literature. 


\section{RESULTS}

\section{Survival following acute thermal stress}

Mussels from the 7 sites acclimated to common conditions showed significant differences in survival during an acute thermal stress event (Fig. 2, log-rank/ Mantel-Cox test, $\mathrm{p}<0.001$ ). Mussels from Tatoosh showed the lowest survival over the $2 \mathrm{wk}$, whereas mussels from Punta Morro and Bodega Bay showed no mortality. Bonferroni corrected pairwise comparisons showed that Tatoosh mussels had significantly lower survival than mussels from all other sites except Boiler Bay. A log-rank test for trend was implemented to determine whether median survival varied with latitude. This test showed a significant relationship between latitude and survival ( $\mathrm{p}<$ 0.001). This latitudinal trend remained when the Tatoosh population was removed from the analysis.

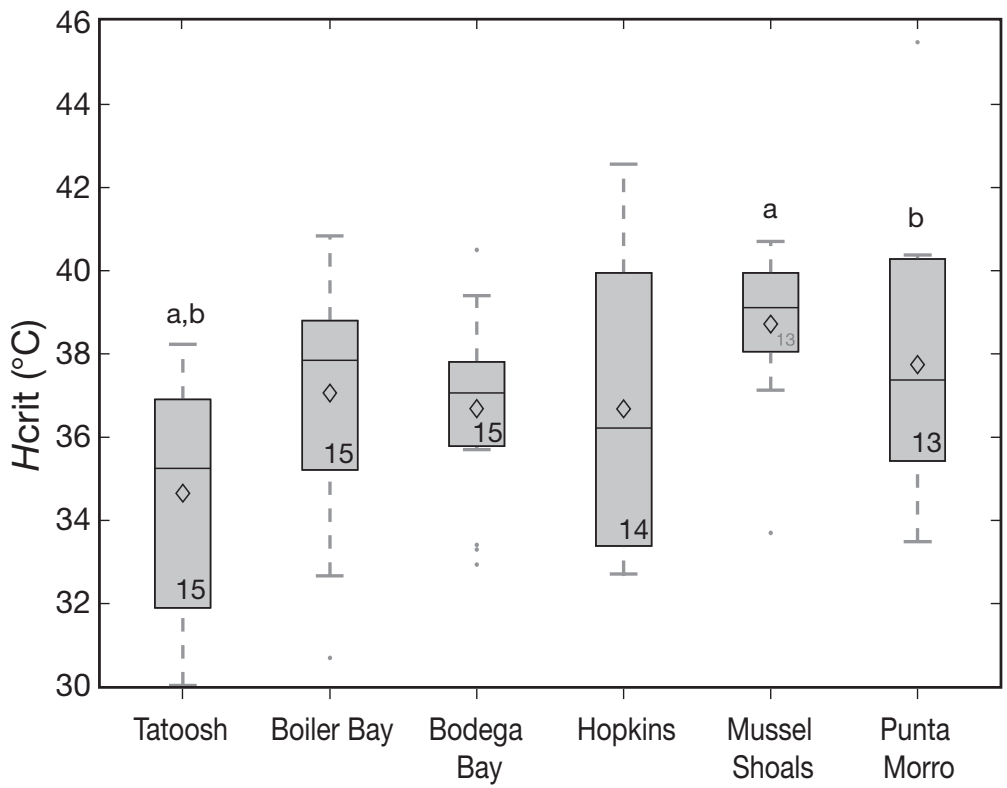

Fig. 3. Critical heart rate temperature (Hcrit) differences between Mytilus californianus populations acclimated to flow-through seawater common conditions for at least $6 \mathrm{wk}$. Box edges represent the 25th and 75th percentiles, lines are medians, and diamonds are means. Letters represent significant differences between paired sites. $\mathrm{N}$ value per site is shown in the bottom right corners

\section{Heart rate and critical temperature measurements}

We measured critical heart rate (Hcrit) temperatures for 13 to 15 individuals acclimated to common conditions from each site except for Port Townsend, where we had too few individuals of the correct size range. Among sites, Hcrit (mean $\pm \mathrm{SE}$ ) ranged between 34.7 $\pm 0.7^{\circ} \mathrm{C} \mathrm{SE}$ (Tatoosh) and $38.5 \pm 0.6^{\circ} \mathrm{C}$ (Mussel Shoals; Fig. 3). The other sites' Hcrit mean values were $36.7 \pm$ $0.6^{\circ} \mathrm{C}$ (Bodega Bay), $36.7 \pm 0.9^{\circ} \mathrm{C}$ (Hopkins), $37.1 \pm$ $0.8^{\circ} \mathrm{C}$ (Boiler Bay), and $37.8 \pm 0.9^{\circ} \mathrm{C}$ (Punta Morro). The mean $H$ crit values among sites were significantly different (1-way ANOVA, $\mathrm{df}=87, F=3.07, \mathrm{p}=0.014$ ). The SNK post hoc test revealed 2 significant pairs. The mean Hcrit from Tatoosh mussels was significantly lower than Mussel Shoals and Punta Morro mussels. However, there was no significant relationship between $H$ crit and latitude when the Tatoosh site was removed (post hoc test for linear trend, $\mathrm{p}=0.378$ ).

\section{MDH activity}

The 10 field-acclimatized individuals from each of the 5 sites tested were significantly different in the activity of MDH (Fig. 4A, 1-way ANOVA, df $=49, F=$ $4.27, \mathrm{p}=0.0051)$. Mussels from Tatoosh had signifi- cantly higher MDH activity than those from Boiler Bay and Bodega Bay. The differences observed among all populations, however, did not follow a latitudinal gradient (post hoc test for linear trend, $\mathrm{p}=0.16$ ), nor did they map onto 'hot spots' along the coast where mid-day low tides occur (Fig. 1). We examined a west coast upwelling index (NOAA Pacific Fisheries Environmental Laboratory, www.pfeg.noaa. gov) as a proxy of food availability during the mussel collection time period (June 2009) because higher food availability could increase metabolic rate (Dahlhoff \& Menge 1996). No relationship existed between upwelling index and MDH activity.

Following at least 2 mo of exposure to common conditions in the laboratory, we found several intersite differences in MDH activities (Fig. 4B, 1-way ANOVA, df $=69, F=4.85, \mathrm{p}=0.0004$ ). The lowest activity levels were found in mussels from Punta Morro, Boiler Bay, and Bodega Bay. The SNK post hoc test showed that Punta Morro and Boiler Bay specimens both had significantly lower MDH activity than specimens from Mussel Shoals, Hopkins, and Port Townsend. In addition, the MDH activity of specimens from Bodega Bay was significantly lower than in those from Mussel Shoals. The differences observed did not follow a latitudinal gradient (post hoc test for linear trend, $\mathrm{p}=0.64$ ), nor did they map 
A. Metabolic rate in field-acclimatized mussels

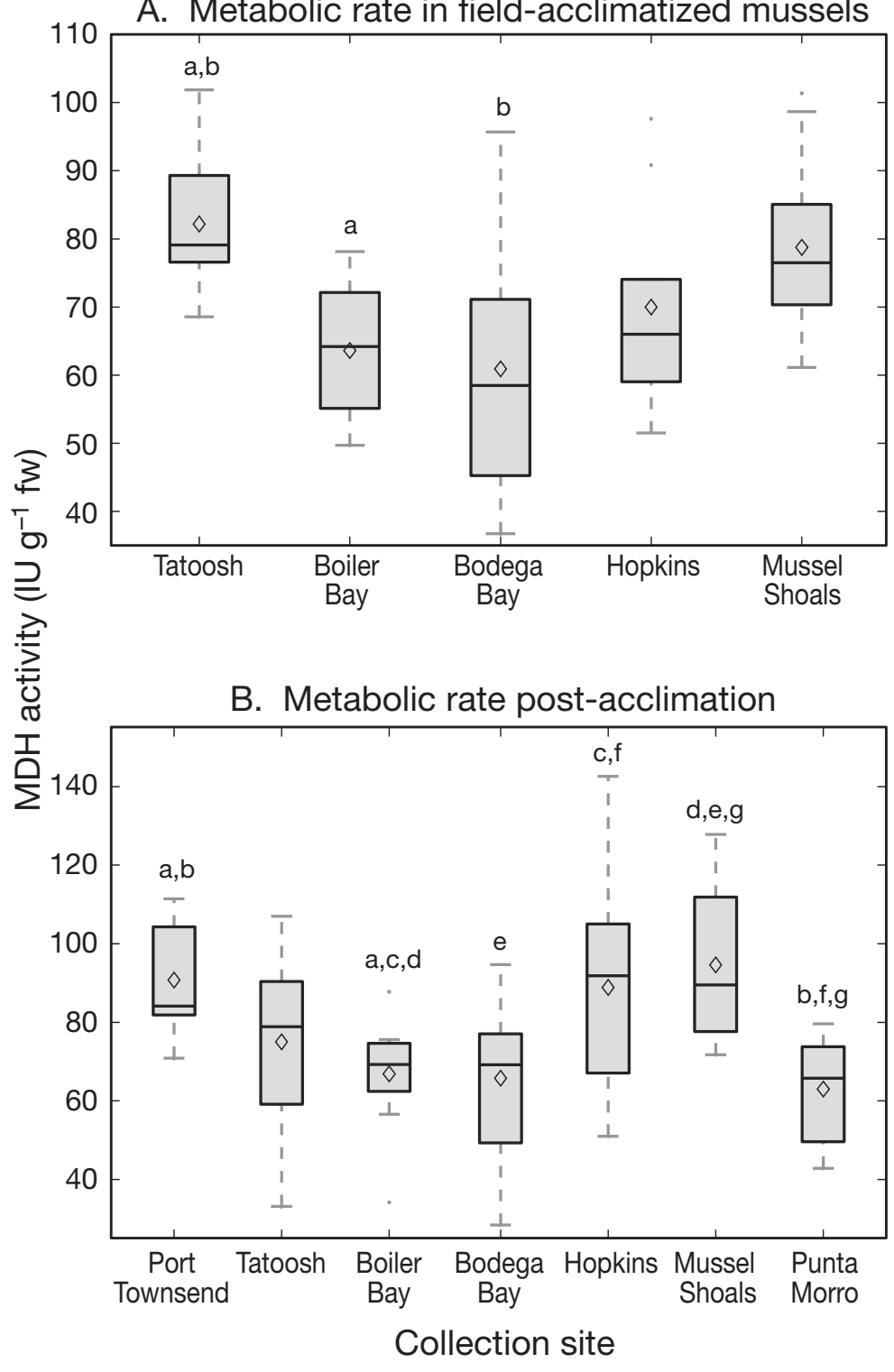

Fig. 4. Metabolic capacity of Mytilus californianus (indexed by malate dehydrogenase, $\mathrm{MDH}$, activity) in (A) field-acclimatized mussels ( $\mathrm{n}=10$ site $^{-1}$ ) and (B) mussels held in common conditions for at least 2 mo $\left(\mathrm{n}=10\right.$ site $\left.^{-1}\right)$. Box edges represent the 25th and 75th percentiles, lines are medians, and diamonds are means. Letters represent significant differences between paired sites. fw: fresh weight

onto 'hotspots' along the coast (Fig. 1). Absolute differences between the field-acclimatized and labacclimated mussels cannot be directly compared, since field-acclimatized mussels were collected during aerial exposure at low tide and underwent an extra freeze-thaw cycle. However, more sites were significantly different following acclimation to common tank conditions than found among sites in fieldacclimatized mussels.

\section{Size and GSI}

To determine whether size-dependence ('scaling') of metabolic rate or reproductive status contributed to the observed differences in MDH activity or Hcrit, linear regression analysis was used to determine the relationship between these variables. Mussels from all sites ranged in size from 7.5 to $9.5 \mathrm{~cm}$ in valve length. There was not a significant relationship between mussel size and $\mathrm{MDH}$ activity in field-acclimatized mussels (linear regression, $\mathrm{R}^{2}<0.001, \mathrm{p}=0.95$ ). There was a small but significant positive correlation between size and MDH activity in post-acclimated mussels (linear regression, $\mathrm{R}^{2}=0.07, \mathrm{p}=0.030$ ), but this correlation did not explain differences found in MDH activity among sites (1way ANOVA, $F=1.61, \mathrm{df}=69, \mathrm{p}=0.16$ ). There was no significant correlation between mussel size and Hcrit (linear regression, $R^{2}=0.02, p=0.21$ ).

Reproductive status was assessed in all mussels for which MDH activity was measured. Field-acclimatized mussels ranged widely in reproductive status between the 5 sites where we were able to immediately flash freeze fresh specimens, from recently spawned to fully ripe $($ mean $=0.49$, range $=0.14-0.81)$. There was no significant difference in GSI among sites (1-way ANOVA, df $=49$, $F=0.11, \mathrm{p}=0.98$ ). However, MDH activity in these mussels did show a small but significant positive correlation with increasing GSI (linear regression, $\mathrm{R}^{2}=0.08$, $\mathrm{p}=0.039$ ).

Following acclimation to common conditions, all mussels had spawned (mean GSI $=0.14$, range $=0.01-0.42$ ), and significant differences in GSI were detected between sites (1-way ANOVA, df $=69$, $F=26.71, \mathrm{p}<0.001)$. The SNK post hoc test showed that Hopkins mussels had a significantly higher GSI than all other sites. Bodega Bay mussels had a significantly lower GSI than mussels from Port Townsend. In this case, however, MDH activity was not correlated to reproductive status (linear regression, $\mathrm{R}^{2}=$ $0.03, p=0.193$ ). Thus, GSI explained small differences in metabolic activity between sites in fieldacclimatized mussels, but not in acclimated mussels. 


\section{Sequencing of cMDH at position 114}

In Mytilus spp., interspecific differences in the ability of $\mathrm{CMDH}$ to bind its cofactor are due to a fixed genetic difference at amino acid site 114 (Fields et al. 2006). A 943 base pair region spanning site 114 was amplified and sequenced for 70 individuals. At position 114, all individuals coded for a charged histidine residue (CAT), the same residue described by Fields et al. (2006) in M. californianus. Thus, no sequence differences were observed in CMDH at position 114.

\section{DISCUSSION}

\section{Evidence for local adaptation to temperature}

Arguably the strongest evidence for local adaptation (or post-settlement selection on genotype) is found in the survival curve obtained for the most northern population studied, Tatoosh Island. The Tatoosh population exhibited the greatest sensitivity to high temperatures in a direct measure of fitness (mortality), consistent with adaptation to the cooler conditions found in its habitat relative to most of the other habitats sampled (Helmuth et al. 2002, 2006). Because mussels had been acclimated to common conditions for at least $6 \mathrm{mo}$, these results indicate that lethal temperature limits are not phenotypically plastic at the adult stage. The Hcrit for cardiac function showed a similar pattern, whereby Tatoosh mussels exhibited the lowest $H$ crit of all populations. In blue mussel congeners, Hcrit shows significant phenotypic plasticity following long-term acclimation to different temperatures (Braby \& Somero 2006b), providing further evidence that this may be genetically fixed in Mytilus californianus. Thus, the differences we observed in cardiac function may contribute to the differences in survival rates following exposure to acute heat stress.

\section{Inter-population differences in MDH activity}

Species adapted to different thermal environments have metabolic characteristics that allow them to function optimally within a thermal window matching their native habitat (Hochachka \& Somero 2002). For many ectotherms, compensation allows an organism adapted to life at low temperature to maintain a higher metabolic rate relative to a related warm-adapted species acclimated to that same low temperature (Hochachka \& Somero 2002). This pat- tern has been observed in comparisons of the blue mussels Mytilus trossulus and M. galloprovincialis (Lockwood \& Somero 2011). Previous studies of $M$. californianus suggest that temperature compensation might occur across the latitudinal range we examined. For example, Rao (1953) found evidence for metabolic compensation of water pumping rates in $M$. californianus across a latitudinal gradient, with higher pumping rates in higher-latitude populations.

In our study of field-acclimatized Mytilus californianus, the most northern population sampled, Tatoosh specimens, exhibited the highest activities of $\mathrm{MDH}$. This difference is consistent with acclimatization to low temperatures; elevated tissue activities of enzymes can offset the reductions in physiological rates due to low temperature (i.e. $Q_{10}$ effects; Hochachka \& Somero 2002). However, mussels from the 'hotspot' at the Mussel Shoals site also had high MDH activity. Overall, MDH activity in fieldacclimatized populations did not correspond to a north to south gradient, nor did it follow the thermal mosaic described by Helmuth et al. $(2002,2006)$ (Fig. 1).

In contrast, another physiological study conducted in latitudinally separated individuals of fieldacclimatized Mytilus californianus showed that transcriptomic fingerprints did appear to correlate with the thermal mosaic (Place et al. 2008). Other explanations for the variation in our study must be considered. Higher metabolic (MDH) activity at the Tatoosh site may have reflected greater food availability (Dahlhoff \& Menge 1996), reproductive status (Dahlhoff et al. 2002), or some other indirect mechanism affecting metabolism in a different spatial mosaic (e.g. biotic interactions). It is unlikely that reproductive status or diet is the explanation, because we found no significant differences between sites in GSI and no evidence of greater upwelling at sites with higher MDH activity. Therefore, the observed differences in field-acclimatized populations are likely due in some measure to other factors that could affect metabolism.

We consider 3 alternatives that might explain siteto-site differences in field-acclimatized mussels. First, MDH plays an important role in anaerobiosis in mollusks, and differences among field populations might have been due in part to the recent history of exposure to different tidal cycles. It is known that prolonged emersion might favor an increased dependence on anaerobic pathways of ATP generation (Gracey et al. 2008). Second, in light of the large and rhythmic variation in transcript for $\mathrm{CMDH}$ that was observed in field populations of Mytilus californianus at another Hopkins site over several tidal cycles 
(Gracey et al. 2008), it is possible that tidal-cyclerelated variation in $\mathrm{MDH}$ activity could have contributed to the differences noted in the field-acclimatized specimens (also see Connor \& Gracey 2011).

Alternatively, fine-scale (meters or less) within-site temperature variability might outweigh the between-site trends that we expected (Denny et al. 2012). If this were the case, we might have collected mussels in a 'colder' portion of the mussel bed at Tatoosh and Mussel Shoals. For example, it may be that mussels collected from the middle of the mussel bed at 1 site were lower on the shore and exposed less to air than mussels collected from other regions. Unfortunately, we do not have a detailed understanding of the within-site temperature variation at our collection sites. Denny et al. (2012) found that within a nearby exposed site at Hopkins, variation in mussel body temperature rivaled variation documented at latitudinal scales. For example, within a natural exposed mussel bed, the mean range of the thermal maximum was $3.7^{\circ} \mathrm{C}$ over $1 \mathrm{mo}$, with a maximum range of $11.7^{\circ} \mathrm{C}$. Although we sampled mussels within a relatively small portion of the mid-intertidal at each site (within a few meters), in situ mussel temperatures may be much more variable and could explain observed differences in field-acclimatized populations. However, Place et al. (2012) showed that within-site transcriptomes in Mytilus californianus were more similar to each other than between site (>65 km) transcriptomes, even at a low, mid-, and high tidal heights (Place et al. 2012). Nevertheless, this result could be confounded by the circadian rhythmicity found in patterns of gene expression in M. californianus (Gracey et al. 2008, Connor \& Gracey 2011), since mussels were not sampled at multiple time points. Future studies should carefully measure fine-scale temperature variation within a site in combination with physiological experiments.

If no population differences existed, we expected that acclimation to common conditions would reduce or eliminate inter-population differences in enzymatic activity. This expectation was not fulfilled. In fact, more sites were significantly different from one another following laboratory acclimation, and relative differences in MDH activity were not consistent with those found in field-acclimatized specimens (Fig. 4). Thus, while our results do support that population differences exist, they do not provide additional support that Tatoosh is a cold-adapted population as found in acute thermal tolerance survival and Hcrit experiments.

MDH activity levels following laboratory acclimation are not explained by acclimatory temperature compensation, at least based on hotspots or latitudinal differences. If acclimatory compensation occurred, one might expect to see the cold-acclimatized mussels decrease their MDH activity during acclimation to common conditions and vice versa for warm-acclimatized mussels. However, acclimatory compensation in MDH activity is not seen in the blue mussel congeners, where both field-acclimatized and common-gardened mussels exhibit the same pattern. The warm-adapted Mytilus galloprovincialis always has lower MDH activity than the cold-adapted congener M. trossulus (Lockwood \& Somero 2011). In $M$. californianus, we do not see evolutionary or acclimatory metabolic temperature compensation in $\mathrm{MDH}$ activity, unless one considers that fine-scale habitat temperature variability might be an underlying driver, as discussed earlier.

MDH activity differences due to diet, tidal cycle, and reproductive status are not likely since mussels had all spawned and were fed the same diet during constant immersion in the flow-through tanks. Another possibility that cannot be ruled out is that populations have different intrinsic levels or rhythms of gene expression for MDH that are fixed genetically or during development (e.g. circadian rhythms), and these might result in persistent differences in $\mathrm{MDH}$ activity even following acclimation to common conditions (Connor \& Gracey 2011). Alternatively, differences in MDH activity could be a result of an adaptive pressure other than temperature.

\section{What are physiologically relevant temperature metrics?}

If the inter-population differences in thermally sensitive traits that we measured are a result of local adaptation to temperature, it is worth considering which temperature metric might best describe the physiological patterns. The latitudinal pattern that we found in survival rates following acute heat stress would indicate that a temperature metric that varies with latitude, such as water temperature, could be more important than those used to describe a thermal mosaic along the coast (Helmuth et al. 2002, 2006). Average daily maximum and summer maximum may not be the most important driver for influencing physiological traits, especially if these traits are set during development. Another possibility is a metric of temperature variability, instead of a mean or maximum temperature. It is known, for example, in limpets, crustaceans, and corals that changes in temperature variability can result in different physiolog- 
ical responses, and the degree of variability could be a selective pressure itself (Sinclair et al. 2006, Rock et al. 2009, Ateweberhan \& McClanahan 2010). Among our study sites, Tatoosh experiences less temperature variability over the year than the other sites (Helmuth et al. 2006), and this population appeared to be the most 'cold-adapted' according to our survival rates to acute heat stress and Hcrit experiments.

\section{Reproductive index correlates with metabolic rate}

Although reproductive index did not explain the differences in MDH activity between sites, we found that more fecund mussels had slightly higher metabolic rates, as indexed by $\mathrm{MDH}$ activity. Respiration in bivalves is influenced by temperature, food, and reproduction (Bayne \& Newell 1983, Sprung 1995, Stoeckmann 2003). Because mussels acclimated to common conditions were controlled for temperature and diet, we conclude that the metabolic rate of Mytilus californianus increases with reproductive tissue weight. The increased energetic demands during reproductive periods may be indicative of an energy trade-off between reproduction and somatic growth (Stoeckmann \& Garton 1997). For this reason, caution should be taken in future studies when using $\mathrm{MDH}$ activity as a biochemical indicator of metabolic rate, since activity varies with diet (Dahlhoff \& Menge 1996) and reproductive status.

\section{CONCLUSION}

Latitudinally separate populations of Mytilus californianus exhibited differences in whole-organism thermal tolerance consistent with adaptation to local temperature conditions at Tatoosh. This leaves open the possibility that genetic differences (local adaptation or balanced polymorphism), environmental canalization, or maternal effects may be responsible for variation among populations. The Hcrit value for cardiac function of Tatoosh mussels was also significantly lower than for other sites, perhaps contributing to lower thermal tolerance.

The physiological differences in enzyme activity did not reflect the differences in thermal tolerance observed at the whole-organism level. The latitudinal differences found in MDH activity could be due to within-site temperature variability, fixed genetic or developmental differences in $\mathrm{MDH}$ levels or rhythms, or an adaptive pressure other than temperature. Future studies of this kind should combine fine- scale in situ measurements of temperature and other physical parameters with physiological experiments.

With respect to understanding a species' response to climate change, determining whether physiological differences among populations are due to local adaptation or phenotypic plasticity is critical (Somero 2010). For example, if the differences we observed in whole-organism thermal tolerance are due to local adaptation, then the most northern population that we sampled (Tatoosh) may be unable to achieve a higher thermal tolerance without gene flow from more tolerant populations (Sanford \& Kelly 2011). Conversely, differences due to phenotypic plasticity would imply that each population has the potential to achieve the full range of tolerances found in the species as a whole (Sanford \& Kelly 2011). Subsequent investigations should employ new genetic approaches, such as next generation sequencing, to look for previously undetected genetic differences in Mytilus californianus (e.g. Pespeni et al. 2012) or examine the role of developmental plasticity by breeding and raising different populations of mussels in identical laboratory conditions over multiple generations (e.g. Kuo \& Sanford 2009).

Acknowledgements. We thank E. Dashiell, A. Haupt, S. Jorgensen, A. Kandur, G. Murphy, C. Neufield, C. Pennington, L. Rodriguez, M. Roux and, especially, A. Ramirez for help collecting mussels. We are grateful to E. Cheung, P. Logan, and K. Mattioli for preliminary data collection. We thank S. Palumbi, B. Lockwood, K.A. Smith, and A. Kandur for helpful discussions in regards to data analysis and interpretation. This research was funded by an NSF Graduate Research Fellowship awarded to C.A.L., NSF grant IOS-0718734 to G.N.S., and by the Partnership for the Interdisciplinary Study of Coastal Oceans (PISCO) sponsored by the David and Lucile Packard Foundation and the Gordon and Betty Moore Foundation. This is PISCO publication number 412.

\section{LITERATURE CITED}

Addison JA, Ort BS, Mesa KA, Pogson GH (2008) Rangewide genetic homogeneity in the California sea mussel (Mytilus californianus): a comparison of allozymes, nuclear DNA markers, and mitochondrial DNA sequences. Mol Ecol 17:4222-4232

> Alexander S, Roughgarden J (1996) Larval transport and population dynamics of intertidal barnacles: a coupled benthic oceanic model. Ecol Monogr 66:259-275

> Ateweberhan M, McClanahan T (2010) Relationship between historical sea-surface temperature variability and climate change-induced coral mortality in the western Indian Ocean. Mar Pollut Bull 60:964-970

Bayne BL (1976) Marine mussels, their ecology and physiology. Cambridge University Press, Cambridge

Bayne BL, Newell RC (1983) Physiological energetics of marine molluscs. In: Saleuddin ASM, Wilbur KM (eds) 
The Mollusca, Vol 4. Academic Press, New York, NY, p 407-515

- Braby CE, Somero GN (2006a) Ecological gradients and relative abundance of native (Mytilus trossulus) and invasive (Mytilus galloprovincialis) blue mussels in the California hybrid zone. Mar Biol 148:1249-1262

> Braby CE, Somero GN (2006b) Following the heart: temperature and salinity effects on heart rate in native and invasive species of blue mussels (genus Mytilus). J Exp Biol 209:2554-2566

> Caley MJ, Carr MH, Hixon MA, Hughes TP, Jones GP, Menge BA (1996) Recruitment and the local dynamics of open marine populations. Annu Rev Ecol Syst 27: 477-500

> Connor KM, Gracey AY (2011) Circadian cycles are the dominant transcriptional rhythm in the intertidal mussel Mytilus californianus. Proc Natl Acad Sci USA 108: 16110-16115

> Conover D, Clarke L, Munch S, Wagner G (2006) Spatial and temporal scales of adaptive divergence in marine fishes and the implications for conservation. J Fish Biol 69: 21-47

$>$ Dahlhoff EP (2004) Biochemical indicators of stress and metabolism: applications for marine ecological studies. Annu Rev Physiol 66:183-207

> Dahlhoff EP, Menge BA (1996) Influence of phytoplankton concentration and wave exposure on the ecophysiology of Mytilus californianus. Mar Ecol Prog Ser 144:97-107

> Dahlhoff EP, Stillman JH, Menge BA (2002) Physiological community ecology: variation in metabolic activity of ecologically important rocky intertidal invertebrates along environmental gradients. Integr Comp Biol 42: 862-871

> Denny MW, Dowd W, Bilir L, Mach KJ (2011) Spreading the risk: small-scale body temperature variation among intertidal organisms and its implications for species persistence. J Exp Mar Biol Ecol 400:175-190

- Farrell T, Bracher D, Roughgarden J (1991) Cross-shelf transport causes recruitment to intertidal populations in central California. Limnol Oceanogr 36:279-288

> Feely RA, Sabine CL, Hernandez-Ayon JM, Ianson D, Hales B (2008) Evidence for upwelling of corrosive 'acidified' water onto the continental shelf. Science 320:1490-1492

Fields PA, Rudomin EL, Somero GN (2006) Temperature sensitivities of cytosolic malate dehydrogenases from native and invasive species of marine mussels (genus Mytilus): sequence-function linkages and correlations with biogeographic distribution. J Exp Biol 209:656-667

> Gaines S, Bertness M (1992) Dispersal of juveniles and variable recruitment in sessile marine species. Nature 360: 579-580

> Gracey AY, Chaney ML, Boomhower JP, Tyburczy WR, Connor K, Somero GN (2008) Rhythms of gene expression in a fluctuating intertidal environment. Curr Biol 18: 1501-1507

Hedgecock D (1986) Is gene flow from pelagic larval dispersal important in the adaptation and evolution of marine invertebrates? Bull Mar Sci 39:550-564

Helmuth B, Harley C (2003) Local- and regional-scale effects of wave exposure, thermal stress, and absolute verses effective shore level on patterns of intertidal zonation. Limnol Oceanogr 48:1498-1508

- Helmuth B, Harley C, Halpin P, O'Donnell M, Hofmann G, Blanchette C (2002) Climate change and latitudinal pat- terns of intertidal thermal stress. Science 298:1015-1017

> Helmuth B, Broitman B, Blanchette C, Gilman S and others (2006) Mosaic patterns of thermal stress in the rocky intertidal zone: implications for climate change. Ecol Monogr 76:461-479

Hochachka PW, Somero GN (2002) Biochemical adaptation: mechanism and process in physiological evolution. Oxford University Press, New York, NY

Hofmann G, Somero G (1996) Interspecific variation in thermal denaturation of proteins in the congeneric mussels Mytilus trossulus and M. galloprovincialis: evidence from the heat-shock response and protein ubiquitination. Mar Biol 126:65-75

Kawecki T, Ebert D (2004) Conceptual issues in local adaptation. Ecol Lett 7:1225-1241

Kelly RP, Palumbi SR (2010) Genetic structure among 50 species of the northeastern pacific rocky intertidal community. PLoS One 5:e8594

Kuo E, Sanford E (2009) Geographic variation in the upper thermal limits of an intertidal snail: implications for climate envelope models. Mar Ecol Prog Ser 388:137-146

> Levin LA (2006) Recent progress in understanding larval dispersal: new directions and digressions. Integr Comp Biol 46:282-297

Levinton J, Suchanek T (1978) Geographic variation, niche breadth and genetic differentiation at different geographic scales in the mussels Mytilus californianus and M. edulis. Mar Biol 49:363-375

> Lockwood BL, Somero GN (2011) Invasive and native blue mussels (genus Mytilus) on the California coast: the role of physiology in a biological invasion. J Exp Mar Biol Ecol 400:167-174

> Menge B, Daley B, Wheeler P, Dahlhoff E, Sanford E, Strub P (1997) Benthic-pelagic links and rocky intertidal communities: bottom-up effects on top-down control? Proc Natl Acad Sci USA 94:14530-14535

> Mislan K, Wethey D, Helmuth B (2009) When to worry about the weather: role of tidal cycle in determining patterns of risk in intertidal ecosystems. Glob Change Biol 15: 3056-3065

Palumbi S (2004) Marine reserves and ocean neighborhoods: the spatial scale of marine populations and their management. Annu Rev Environ Resour 29:31-68

Pespeni MH, Garfield DA, Manier MK, Palumbi SR (2012) Genome-wide polymorphisms show unexpected targets of natural selection. Proc R Soc Lond B Biol Sci 297: 1430-1436

> Petes L, Menge B, Harris A (2008) Intertidal mussels exhibit energetic trade-offs between reproduction and stress resistance. Ecol Monogr 78:387-402

> Place SP, O'Donnell MJ, Hofmann GE (2008) Gene expression in the intertidal mussel Mytilus californianus: physiological response to environmental factors on a biogeographic scale. Mar Ecol Prog Ser 356:1-14

Place SP, Menge BA, Hofmann GE (2012) Transcriptome profiles link environmental variation and physiological response of Mytilus californianus between Pacific tides. Funct Ecol 26:144-155

> Possingham H, Roughgarden J (1990) Spatial population dynamics of a marine organism with a complex life cycle. Ecology 71:973-985

$>$ Rao KP (1953) Rate of water propulsion in Mytilus californianus as a function of latitude. Biol Bull (Woods Hole) 104: $171-181$ 
Rock J, Magnay JL, Beech S, El Haj AJ, Goldspink G, Lunt DH, White NM (2009) Linking functional molecular variation with environmental gradients: myosin gene diversity in a crustacean broadly distributed across variable thermal environments. Gene 437:60-70

Roughgarden J, Iwasa Y, Baxter C (1985) Demographic theory for an open marine population with space-limited recruitment. Ecology 66:54-67

Sanford E, Kelly MW (2011) Local adaptation in marine invertebrates. Annu Rev Mar Sci 3:509-535

Sarver S, Foltz D (1993) Genetic population structure of a species' complex of blue mussels (Mytilus spp.). Mar Biol 117:105-112

Sinclair ELE, Thompson MB, Seebacher F (2006) Phenotypic flexibility in the metabolic response of the limpet Cellana tramoserica to thermally different microhabitats. J Exp Mar Biol Ecol 335:131-141

Somero GN (2010) The physiology of climate change: how potentials for acclimatization and genetic adaptation will determine 'winners' and 'losers'. J Exp Biol 213: 912-920

Sprung M (1995) Physiological energetics of the zebra mus-

Editorial responsibility: Roger Hughes,

Bangor, UK sel Dreissena polymorpha in lakes. II. Food uptake and gross growth efficiency. Hydrobiologia 304:133-146

Stoeckmann A (2003) Physiological energetics of Lake Erie dreissenid mussels: a basis for the displacement of Dreissena polymorpha by Dreissena bugensis. Can J Fish Aquat Sci 60:126-134

Stoeckmann AM, Garton DW (1997) A seasonal energy budget for zebra mussels (Dreissena polymorpha) in western Lake Erie. Can J Fish Aquat Sci 54:2743-2751

Strathmann MF (1987) Reproduction and development of marine invertebrates of the northern Pacific coast: data and methods for the study of eggs, embryos, and larvae. University of Washington Press, Seattle, WA

Trevelyan G, Chang E (1983) Experiments on larval rearing of the California mussel (Mytilus californianus). J World Maric Soc 14:137-148

Yang TH, Somero GN (1993) Effects of feeding and food deprivation on oxygen consumption, muscle protein concentration and activities of energy metabolism enzymes in muscle and brain of shallow-living (Scorpaena guttata) and deep-living (Sebastolobis alascanus) scorpaenid fishes. J Exp Biol 181:213-232

Submitted: October 12, 2010; Accepted: November 9, 2011 Proofs received from author(s): March 18, 2012 